\title{
A CAMINHADA FORMATIVA NO PROGRAMA RESIDÊNCIA PEDAGÓGICA NA LICENCIATURA EM EDUCAÇÃO DO CAMPO CIÊNCIAS DA NATUREZA: reflexões pedagógicas em construção
}

\section{Cherlei Marcia Coan ${ }^{1}$ Marciane Maria Mendes ${ }^{2}$ \\ VANDERLEIA DARTORA ${ }^{3}$}

Introdução

O processo formativo que apresentamos neste capítulo ocorreu no âmbito do Programa Residência Pedagógica (PRP), vinculado ao subprojeto da Licenciatura em Educação do Campo (LEdoC), da Universidade Federal da Fronteira Sul (UFFS). Para o desenvolvimento deste trabalho foi estabelecida uma parceria entre os campi

\footnotetext{
1 Mestre em Educação, professora da UFFS, coordenadora de núcleo do Programa Residência Pedagógica em Educação do Campo, campus Erechim. Contato: cherlei. coan@uffs.edu.br.

${ }^{2}$ Doutora em Educação pela UFPR, professora-adjunta pela UFFS, coordenadora-adjunta do Curso Interdisciplinar em Educação do Campo: Ciências Naturais, Matemática e Ciências Agrárias, coordenadora do núcleo do Programa Residência Pedagógica, campus Laranjeiras do Sul. Contato: marciane.mendes@uffs.edu.br.

3 Mestre em Geografia, professora substituta do UFFS, colaboradora de núcleo do Programa Residência Pedagógica em Educação do Campo, campus Erechim. Contato: vanderleia.dartora@yahoo.com.br.
} 
Erechim, RS, e Laranjeiras do Sul, PR, que ofertam na LEdoC a habilitação em Ciências da Natureza. No Paraná, o curso acontece em regime regular noturno, já no Rio Grande do Sul, o curso é ofertado em regime de alternância, com aulas quinzenais e intensivos nos meses de julho e janeiro.

Considerando os desafios da formação de educadores do campo na LEdoC, destacamos a formação por área do conhecimento para a docência multidisciplinar, a criação de vínculos com as escolas existentes nos territórios de origem dos educandos que estão cursando a LEdoC e a prioridade no acesso dos sujeitos do campo ao ensino superior público, por isso, o PRP se constitui mais um importante espaço de formação docente, fortalecendo a articulação da universidade e de seus docentes e discentes ao trabalho nas escolas de Educação Básica e com os professores da área de Ciências da Natureza.

Para pensar o PRP na LEdoC, alguns pressupostos centrais foram estruturantes na organização da nossa proposta: a) os conhecimentos acadêmicos são imprescindíveis para a formação profissional, mas são insuficientes quando considerados prontos como um fim em si mesmos, já que eles precisam dialogar com questões da realidade concreta dos estudantes; b) é preciso um ensino de Ciências que dialogue com a cultura dos sujeitos do campo e, nesse processo, seja possível valorizar saberes científicos e tradicionais; e c) uma leitura mais atenta e crítica da realidade vivida pela comunidade escolar possibilita construir caminhos para superar um ensino meramente propedêutico e a fragmentação disciplinar. É importante ressaltar que não se trata de negar ou diminuir os conhecimentos acadêmicos, nosso argumento tenciona criar a hierarquização dos conhecimentos. No contexto do programa se faz necessária a reflexão acerca da organização e da validação dos conhecimentos das Ciências, sobretudo das Ciências da Natureza, por meio de uma 
proposta de tomar como ponto de partida os conhecimentos de cada realidade escolar e aprofundar sua compreensão crítica no encontro com a cultura acadêmica.

Diante desse contexto apresentado, temos a intenção de analisar a primeira fase do PRP denominada, em Erechim, de Levantamento Preliminar da Realidade Local e, em Laranjeiras, de Inventário da Realidade. O esforço nessa fase foi coletar informações e imergir na comunidade buscando conhecer e reconstruir elementos históricos, sociais, culturais, ambientais e econômicos das realidades investigadas, assim como entender as potencialidades e as fragilidades de propor uma intervenção pedagógica estruturada por temas identificados junto à comunidade escolar na perspectiva de formar professores que possam construir currículos de Ciências da Natureza contextualizados nas suas realidades socioculturais.

Ao longo do texto, faremos uma breve análise da caminhada até o momento percorrida na organização das ações do programa em andamento, assim como a reflexão acerca das compreensões dos bolsistas residentes e docentes preceptoras acerca do papel de reunir informações, depoimentos, fotos, vídeos, dados estatísticos e referenciais teóricos, da realidade local para o planejamento pedagógico das ações de intervenção que constituirão a segunda fase do processo formativo de docência na área de Ciências da Natureza em escolas do campo e indígenas.

\section{A Formação de Professores de Ciências da Natureza na Licenciatura em Educação do Campo e as Ações do Programa Residência Pedagógica}

As Licenciaturas em Educação do Campo, implantadas a partir de meados da primeira década do século XXI, surgiram com o nobre propósito de combater às desvantagens educacionais históricas 
sofridas pelas populações rurais e valorizar a diversidade nas políticas educacionais, sobretudo, na formação superior. Sendo uma conquista dos movimentos sociais, demandada como prioridade durante a II Conferência Nacional por uma Educação do Campo, em 2004, o desenho curricular da LEdoC considera as especificidades da vida no campo. Para isso, foram fundamentais as referências dos cursos desenvolvidos no âmbito do Programa Nacional de Educação na Reforma Agrária.

Com a implantação de 42 novos cursos de Educação do Campo em IES públicas (MOLINA; HAGE, 2016), tem-se permitido o acesso de parte da população que antes era excluída da formação superior, como os sujeitos do campo. O Decreto n. 7.352/2010, em seu artigo $1^{\circ}$, define os sujeitos do campo a partir de sua sociodiversidade:

Para os efeitos deste decreto entende-se por: [...] I - populações do campo: os agricultores familiares, os extrativistas, os pescadores artesanais, os ribeirinhos, os assentados e acampados da reforma agrária, os trabalhadores assalariados rurais, os quilombolas, os caiçaras, os povos da floresta, os caboclos e outros que produzam suas condições materiais de existência a partir do trabalho no meio rural. (BRASIL, 2010, art. $1^{\circ}$ )

Tem-se como propósito tratar da formação de professores do campo, reconhecendo suas especificidades, em contraposição a um projeto de formação generalizada e homogeneizadora, que não considera a diversidade dos sujeitos do campo, fato que nos estimula a refletir também sobre as especificidades da docência e de seus processos formativos na LEdoC. Assim, a formação de educadores do campo não pode tomar como referência um modelo tradicional de formação, ao contrário disso, é necessário um processo formativo no qual os docentes reconheçam sua responsabilidade na articulação da escola com os projetos sociais e econômicos do campo (ARROYO, 2011), bem como um educador que adquira uma atitude reflexiva 
acerca de suas práticas para que possa se assumir como uma liderança na transformação das realidades das comunidades.

A Educação do Campo tem como ponto de partida de seus processos formativos a realidade concreta das pessoas que vivem e produzem a sua existência no campo. Procura compreender as relações históricas, sociais e culturais que se consolidam nos diferentes contextos a fim de planejar seus processos formativos. Freire (2008, p. 11) argumenta sobre o movimento ação-reflexão-ação, quando propõe que "a leitura do mundo precede a leitura da palavra", assim como o ato de ler palavras implica, necessariamente, uma contínua releitura do mundo.

Quando Freire (2014) defende a educação como um ato político, entende-se que é um esforço de denunciar muitas das contradições sociais da nossa realidade e, ao mesmo tempo, anunciar um outro papel para a escola, que vai muito além do mero papel de transmissora do conhecimento acumulado pela humanidade. Nas palavras de Freire (2016, p. 109),

E não se diga que, se sou professor de biologia, não posso me alongar em considerações outras, que devo apenas ensinar biologia, como se o fenômeno vital pudesse ser compreendido fora da trama histórico-social, cultural e política. Como se a vida, a pura vida, pudesse ser vivida de maneira igual em todas as suas dimensões favela, no cortiço ou numa zona feliz dos "Jardins" de São Paulo. Se sou professor de biologia, obviamente, devo ensinar biologia, mas, ao fazê-lo, não posso seccioná-lo daquela trama.

Contrapõe-se a uma concepção de conhecimento que intenciona apenas transferir ou depositar uma "verdade" aos sujeitos. Freire (2011, p. 28) argumenta que o processo de conhecer exige a "presença curiosa do sujeito em face do mundo", já que conhecimento não é sinônimo de depósito de conteúdos em "consciências ocas" (FREIRE, 2011). O conhecimento se constrói nas relações homem-mundo e vai se aperfeiçoando na problematização crítica dessas relações. 
O diálogo se inicia na busca pelo conteúdo programático, antes mesmo da situação pedagógica que envolve educador e educandos no processo da investigação temática. Freire defende que não há diálogo se não há a convicção da inconclusão humana e a possibilidade do ser mais. Assim, um dos primeiros diálogos que se coloca na docência dos licenciandos é a definição da temática que contextualiza os conteúdos de Ciências da Natureza a serem trabalhados. Esse tema precisa emergir do contexto investigado, daquilo que foi entendido ao longo do levantamento preliminar da realidade local como importante de ser problematizado sobre a realidade da escola, a fim de que os estudantes compreendam melhor a realidade que estão vivendo para atuar nela, buscando sua transformação e a humanização dos sujeitos.

Com isso, Freire (2014) argumenta que o tema também precisa ser definido de forma horizontal, dialógica, buscando compreender como os educandos percebem sua realidade, qual sua visão de mundo, quais são suas aspirações. Ou seja, o “[...] conteúdo do quefazer educativo nasce dos camponeses mesmos, de suas relações com o mundo, e vai-se transformando, ampliando, na medida em que este mundo se lhes vai desvelando" (FREIRE, 2011, p. 123). Nesse sentido, vamos delineando uma concepção de educação e de ensino de Ciências da Natureza bem distante da pura transmissão de conhecimentos, em que a própria escola estabelece o seu conteúdo a partir de referências do campo disciplinar.

Conhecer e valorizar o pensar do outro não significa permanecer nele, é necessário oportunizar novas formas de pensar. Apreender as distintas visões sobre a situação significativa que está sendo desvelada, bem como compreender a visão que a comunidade tem acerca dessa situação, está próximo do papel de professor como "educador-educando". Aquele que ao mesmo tempo ensina, também aprende o modo como o outro explica a situação investigada. 
Portanto, um dos possíveis caminhos a trilhar na formação de professores para a Educação do Campo com habilitação em Ciências da Natureza é o diálogo entre os saberes populares e o conhecimento científico de maneira dialética. Todos os sujeitos sociais (movimentos sociais, lideranças comunitárias, professores, comunidade escolar, estudantes, entre outros) precisam fazer parte da construção dessa proposta curricular, pois esse processo deve atender às necessidades e às especificidades dos povos do campo.

\section{Caminhos Metodológicos}

Na LEdoC enfrentamos o desafio da formação de professores, articulada à diversidade cultural de nossos alunos. Entre os acadêmicos do curso, temos indígenas da etnia kaingang e guaranis, bem como representantes de movimentos sociais (Movimento dos Trabalhadores e Trabalhadoras Sem Terra (MST), Movimento dos Atingidos por Barragens (MAB), Movimento das Mulheres Camponesas (MMC), entre outros), filhos de pequenos agricultores e alguns professores que já atuam nas escolas do campo ou escolas indígenas e procuram aprimorar sua formação para exercer a função docente. Essa diversidade cultural é uma potencialidade do curso, mas também sinaliza novos desafios e muitas demandas inéditas ao grupo de docentes formadores da LEdoC.

O grupo de bolsistas residentes é formado por 16 estudantes do campus Erechim, RS, e oito do campus Laranjeiras do Sul, PR. Fazem parte do grupo de residentes de Erechim 14 indígenas kaingang, cinco deles já atuam como professores na escola da aldeia, uma estudante filha de agricultores familiares e outra produtora rural que também compõem o coletivo do Movimento das Mulheres Camponesas. No caso de Laranjeiras do Sul, dos oito bolsistas que compõem o PRP, uma estudante é filha de pequenos agricultores 
assentados, outra é produtora rural, temos ainda uma filha de pequenos agricultores da comunidade de Passo Liso e duas estudantes residem no município de Cantagalo, PR. Do total de estudantes residentes, cinco vivem no meio urbano de Laranjeiras do Sul, PR.

É importante dizer que o grupo de acadêmicos residentes dedicou-se no primeiro semestre à realização do que chamamos de levantamento preliminar da realidade local ou inventário da realidade. Então, a partir do Edital do Programa, pode-se dizer que a metodologia constitui-se na pesquisa-ação qualitativa, que, segundo Demo (1992 apud TOZONI-REIS, 2010, p. 49), é uma alternativa de pesquisa que coloca a ciência a serviço da emancipação social, trazendo duplo desafio: o de pesquisar e o de participar, o de investigar e educar, realizando a articulação entre teoria e prática no processo educativo.

Ainda merece destaque o planejamento, o acompanhamento e a avaliação permanentes das ações do PRP de um grupo de docentes formadoras da LEdoC e pelas docentes preceptoras que atuam nas escolas cadastradas. Em Charrua, atuamos na Escola Estadual Indígena de Ensino Médio Fág Mág, localizada na Aldeia Ligeiro, e na Escola Estadual de Ensino Médio Inglês de Sousa, situada na área urbana do município. Já em Laranjeiras do Sul, atuamos no Colégio Estadual do Campo Joany Guilherme de Lima - Ensino Fundamental e Médio, localizado no distrito de Passo Liso. Sendo esse o único distrito de Laranjeiras do Sul, o qual agrega várias comunidades rurais vizinhas que compõem uma heterogeneidade camponesa. Um dos desafios que os povos do campo encontram é o reconhecimento e a valorização de sua cultura, em especial no espaço educacional.

Consideramos que a escola se constitui em um dos principais espaços na vida dos jovens, é nela que o processo de reflexão se desenvolve pela prática dialógica e problematizadora, favorecendo diferentes leituras de mundo e possibilitando condições para que "[...] 
sejam produzidas as bases de uma nova sociedade que se contraponha ao modelo gerador de desigualdades e exclusão social que impera nas políticas educacionais de inspiração neoliberal" (PARANÁ, 2008, p. 11).

Buscando inverter a perspectiva de construção curricular, que, tradicionalmente, parte de conteúdos disciplinares preestabelecidos, propomos partir da realidade e do contexto dos estudantes. Para isso, foi organizado coletivamente um roteiro de perguntas estruturado a partir de quatro eixos: aspectos históricos, sociais, culturais e pedagógicos das comunidades investigadas. Os bolsistas foram divididos em grupos para atender a cada um dos eixos e reunir uma espécie de diagnóstico da realidade local que seria a base para o levantamento dos temas a serem abordados na fase seguinte do PRP que sinaliza para a intervenção junto aos estudantes da escola. O conjunto de dados coletados foi organizado na forma de um texto e compôs o dossiê. Além desse documento, são tomados como fontes de análise as respostas de bolsistas e de docentes preceptoras a um questionário.

Foram organizados dois momentos avaliativos formais com o grupo do programa: uma roda de conversa com o intuito de descobrir os avanços e as dificuldades vivenciados e socializados pelo grupo no $1^{\circ}$ Seminário Multicampi de Avaliação do Programa Residência Pedagógica, e a aplicação de um questionário de avaliação dessa primeira fase, enviado por $e$-mail às três preceptoras e aos 24 bolsistas residentes. Apenas dois bolsistas residentes não retornaram com o instrumento respondido. Tanto o roteiro de tópicos a serem avaliados quanto o instrumento aplicado buscavam entender as concepções do grupo acerca da importância e do papel do levantamento preliminar da realidade local; as potencialidades do programa na formação docente de cada sujeito; as sugestões que poderiam qualificar o trabalho em desenvolvimento e as dificuldades enfrentadas nessa vivência. Foram criados códigos para identificar os sujeitos, 
sendo que a letra $\mathrm{E}$ identifica os entrevistados da comunidade local, a letra $\mathrm{P}$ identifica as preceptoras e a letra $\mathrm{R}$ identifica os residentes.

\section{Apontamentos e Reflexões na Formação de Professores de Ciências da Natureza - Novos Conhecimentos, Outras Ações}

O processo formativo voltado para a docência na área de Ciências da Natureza proporcionado pela primeira fase do PRP foi essencialmente produtor de sentidos a todos os sujeitos envolvidos nesse movimento. Contamos com a participação direta de três docentes formadoras da UFFS, três professoras preceptoras que atuam nas escolas de Educação Básica vinculadas ao programa e 24 bolsistas, acadêmicos da LEdoC.

No processo de levantamento preliminar da realidade local, muitos foram os diálogos estabelecidos. Merecem destaque as rodas de conversas com os kofás, os indígenas mais velhos, identificados pelos acadêmicos kaingang como sendo a memória viva da comunidade, responsáveis pelos relatos das histórias antigas e dos modos de vida do seu povo, propagando assim a cultura de uma geração a outra.

O espaço de diálogo com a equipe da Unidade de Saúde, formada por enfermeiras, dentista, agentes de saúde e, na época, por um médico cubano, evidenciou com muita força a relação entre a cultura local e as formas de tratamento convencionais da saúde, ou melhor, da falta dela. Chamou atenção do grupo as estatísticas relacionadas a enfermidades como a hipertensão e diabetes, as doenças sexualmente transmissíveis, sobretudo a sífilis, o abuso de bebidas alcoólicas destiladas e a resistência em realizar exames periódicos preventivos e usar medicação contínua. Ainda foram canais de comunicação outras lideranças comunitárias, entre elas, destacamos os sujeitos identificados pelos residentes como conhecedores das plantas medicinais 
e práticas alternativas, além da equipe diretiva das escolas, professores aposentados e em exercício, bem como a seleção e o estudo de textos sobre o local (teses, dissertações, artigos).

Se, por um lado, esses "confrontos" de saberes geram tensões, silêncios, desconfortos; por outro, a acolhida, a compreensão e o desejo por novos conhecimentos fortalecem vínculos entre o coletivo, facilitando o espaço de fala, a apresentação de ideias e a exposição de fragilidades pessoais. A fala de uma residente nos mostra elementos em direção à superação de dificuldades pessoais: “[...] através do programa eu consegui melhorar na escrita como acadêmica. E aprendi a me expressar de forma mais clara no diálogo, a defender minhas opiniões sobre o que penso" ( $R$ 8).

Os encontros e diálogos entre os residentes, as preceptoras, as professoras da UFFS e a comunidade em geral reafirmaram os diferentes olhares sobre a realidade, distintas explicações e sentimentos envolvidos, formas diversas de construir conhecimentos, como pode ser exemplificado pela fala de uma moradora local "[...] quando eu nasci os meus pais já faziam o artesanato, daí foi com eles que eu aprendi a fazer, porque isso passa de geração para geração [...]” (E 3). $\mathrm{O}$ conhecimento indígena é construído coletivamente, nas atividades cotidianas, com a participação de todas as pessoas da comunidade. Com o programa foram ficando evidentes diferentes crenças, tradições e práticas socioculturais e econômicas que retratam formas distintas de ver o mundo e compreender os fenômenos que envolvem a vida e o ensino de ciências.

Para os residentes, o levantamento preliminar da realidade local possibilitou conhecer melhor aspectos culturais, históricos, sociais, econômicos e ambientais da comunidade, permitindo um "[...] olhar de forma diferente para esta mesma realidade" ( $R$ 1). Foi um momento de descobrir e de aprender "[...] muitas coisas do passado, que nós residentes não sabíamos e mesmo assim esses aprendizados e histórias faziam parte da nossa vida e dos nossos antepassados" 
( $R$ 7). Essa imersão com um novo olhar para a comunidade gerou uma "[...] aproximação maior de todos, tanto de alunos, professores, quanto de pessoas da comunidade envolvidas no tema, trazendo uma confiança maior" ( $R$ 13). Confiança que se transforma em segurança no momento de planejamento das atividades docentes e colabora nas discussões acerca dos conhecimentos tradicionais, dos conhecimentos científicos e dos conhecimentos escolares.

A identificação e o estudo de temas que surgem da realidade local têm despertado nos residentes um maior envolvimento na identificação de situações contraditórias vividas pela população. Como exemplo, podemos citar as mudanças nos hábitos alimentares, antes tendo como base a coleta do mel, do pinhão, das folhas e frutos nativos; o consumo de espécies cultivadas como milho, feijão, moranga; a pesca, como retrata a fala dos entrevistados E4 e E 5

Antigamente a cultura era muito valorizada e respeitada, desde as comidas típicas até as tradições. A refeição da comunidade era a base de caça, do Ëgóró e do Ëmĩ. A caça era feita através da flecha e armadilhas [...]. Os Egóró eram colhidos no mato, tais como kumĩ, fuva (fuá), krunun, jóho, pého féj, pyrfé, grã. As plantas eram colhidas, lavadas e cozidas ou refogadas na banha de porco [...]. O Ėmĩ era feito com a farinha de trigo ou milho verde, a massa era preparada com água e farinha e alguns colocavam sal e sovada com as mãos e o Emĩ de milho verde era ralado e depois socado no pilão em seguida era assado na brasa (E 4).

Cada família tinha uma pequena roça para comer. Criava galinha, porco, vacas, tiravam leite. Banha não faltava, o porco matava para fazer a banha. Sempre fazia salada do mato, polenta, pão na cinza, massa, carne de galinha e porco das criações. A salada era radiche do mato, caraguatá que dá na água, mistura com o feijão, folha de urtigão, broto de abóbora, moranga (E 5).

Atualmente, está muito presente o consumo de alimentos industrializados, como refrigerantes, salgadinhos, enlatados, leites e 
derivados, o que, por um lado, eleva os índices de cáries nas crianças e desestimula a alimentação típica; e, por outro, gera acúmulo de lixo e todos os transtornos advindos dele. Assim, nos perguntamos o que nos leva a deixar de lado alimentos típicos para consumir outros que podem causar danos a nossa saúde e ao meio onde vivemos? O que pode ser feito para minimizar os problemas oriundos dessa nossa opção? Como o ensino de ciências pode contribuir com a reflexão acerca desse cenário e construir ações transformadoras?

Outra situação se refere ao modelo de organização das moradias na forma de "vilas", iniciado na época do Serviço de Proteção ao Índio, que dificulta a "[...] implantação de pequenas lavouras e criação de pequenos, médios e grandes animais para subsistência" (EMILIANO, 2015, p. 85). Contrário a essa lógica, segundo entrevista com um dos anciões da comunidade, as casas costumam ficar espalhadas pelo território, eram as nascentes de água que determinavam os lugares e a quantidade de famílias que poderiam se estabelecer no local, e o acesso à água permitia usá-la "[...] para o consumo da família e para as plantações de milho, mandioca, feijão e para a criação de animais" (E 1).

Reunidos no coletivo de uma das escolas cadastradas no PRP, junto aos demais professores, com membros da equipe do Posto de Saúde, socializamos o dossiê, resultado do trabalho da primeira fase do PRP. A partilha dos dados e dos conhecimentos foi mais um momento importante para se somar às percepções do grupo e eleger o tema para o projeto a ser desenvolvido. As três questões codificadas pelo grupo dos residentes nessa escola girou em torno da falta de água (atribuída à falta de consciência no uso desse bem pela população); do abuso de bebidas alcoólicas destiladas (entendido como um problema individual e que ajuda na desinibição); e o resgate dos elementos culturais vinculados à alimentação típica e ao artesanato, com ênfase nas cestarias e pinturas (nesse eixo, os sentidos primeiros 
é que a alimentação contém muitos produtos industrializados que têm causado sobrepeso e problemas de saúde, além disso, são poucas famílias, sobretudo as mulheres mais idosas, que ainda se dedicam à confecção de artesanatos para sustento familiar, existem objetos ou pinturas que são feitos somente quando acontecem festividades, podendo ser melhor explorada a reflexão do significado das marcas para o povo kaingang).

Após os diálogos estabelecidos se definiu o tema "Educação e Cultura" como norteador do projeto das intervenções pedagógicas na próxima fase do PRP. A escolha do tema considerou as seguintes questões: quais os fatores que influenciam a perda de elementos culturais do povo kaingang pela própria comunidade? O que pode ser feito para promover a valorização e o resgate desses elementos que identificam nossa comunidade? Como pensar o ensino de ciências a partir desses elementos norteadores? A fala de um residente demonstra que ele compreendeu a caminhada proposta e o papel do levantamento preliminar da realidade: "[...] através das informações dadas pela comunidade local, estaremos propondo estudos e fazendo projetos junto com a comunidade, principalmente escolar [...]", refletindo sobre a própria prática docente" ( $R$ 11). Outro argumento que reforça a importância da escrita do dossiê pelos residentes é que "[...] deixando em materiais escritos, o trabalho realizado, para que futuras gerações, indígenas e não indígenas, possam pesquisar sobre a comunidade indígena" (R 3). Ainda é importante frisar que neste trabalho estamos enfatizando a primeira fase do PRP que tem o foco de chegar ao tema, pois a etapa da redução temática que consiste na definição das ações do programa a ser desenvolvido para compreensão do tema já é fruto da preocupação da segunda etapa do trabalho. Entender os conhecimentos da realidade local não pressupõe permanecer neles, isso Freire (2016, p. 97-98) bem esclareceu: 
[...] partir do saber que os educandos tenham não significa ficar girando em torno deste saber. Partir significa pôr-se a caminho, ir-se, deslocar-se de um ponto a outro e não ficar, permanecer. Jamais disse, como às vezes sugerem ou dizem que eu disse, que deveríamos girar embevecidos, em torno do saber dos educandos, como a mariposa em volta da luz. Partir do 'saber de experiência feito’ para superá-lo não é ficar nele.

Cabe destacar que, por questões formais do programa, o movimento de reunir um coletivo maior para os diálogos descodificadores foi realizado em apenas uma das escolas cadastradas, nas outras duas escolas, o diálogo para definição do tema do projeto envolveu apenas os sujeitos diretamente participantes do programa. Entre os residentes, em alguns momentos, tensões se mostraram como dificuldades a serem enfrentadas, demonstradas por algumas falas representativas do grupo:

[...] relação com uma cultura diferente da minha, onde as vezes fui repreendida por colegas residentes, por ser diferente da cultura dos mesmos (R 7).

Aprender a ter responsabilidade sobre as tarefas que nos são propostas e aprender a trabalhar em grupos. (R 8)

Uma das dificuldades levantadas pela preceptora de uma das escolas se relacionou ao fato de não conseguir participar de todos os momentos dos trabalhos do programa, mesmo nos encontros que ocorriam na escola, tendo em vista que precisava atender às suas turmas. Esse aspecto traz à tona a inexistência de condições para acontecer a formação dos professores em exercício nas escolas.

No diálogo entre os docentes formadoras, as docentes preceptoras e os residentes, as tensões foram expressas em silêncios, ou, por vezes, ocorria a não realização de atividades combinadas, sobretudo as que exigiam o ato de escrever. Quanto à resistência com a escrita, 
pensamos que poderia estar relacionada à tradição oral, muito mais presente na cultura kaingang, como também as dificuldades encontradas por serem bilíngues. Com o auxílio de estudos de referenciais que retratam a cultura local e uma postura acolhedora que resultou na criação de vínculos de amizade e respeito, foram se contornando as dificuldades. A fala do residente exemplifica esse aspecto:

Estudo Educação do Campo na UFFS, Erechim, e o projeto [se refere ao Programa Residência Pedagógica] é a realidade de tudo aquilo que a gente vem estudando no curso, nos auxilia ao máximo na nossa formação acadêmica, os nossos professores do Projeto Residência Pedagógica são verdadeiros mestres, são não indígenas, mas seus conhecimentos relatam tudo aquilo que acontece na nossa comunidade, parece que conviveram muito tempo, junto com o nosso povo, a orientação é excelente. A organização de nossos estudos junto da comunidade, feitos pelas nossas orientadoras do programa Residência, nos ensina que devemos ser organizados para atingirmos os nossos objetivos, como futuros professores de nossas comunidades. Essa estratégia é de fundamental importância na nossa formação ( $R$ 3).

Somado a esse depoimento, a diretora da escola também se pronunciou surpresa com a dinâmica construída nesse projeto, conforme expressa sua fala: "[...] na minha graduação não havia essa preocupação com a realidade, com nossa cultura" (E 4). Percebemos que nos encontros e diálogos interculturais, há vozes que são silenciadas e esse processo não é alheio às propostas formativas em escolas e universidades. Denunciar essa forma de opressão, trabalhar para entender as razões e possibilitar outras formas de relações com grupos étnicos distintos são práticas essenciais na LEdoC. Sabemos que ainda é preciso avançar muito, pois, por mais que entendemos a ciência como uma das formas de conhecimento válido para conhecer a realidade, em muitas situações, hierarquizamos ou menosprezamos compreensões distintas da ciência hegemônica, nos 
aproximando do que Freire (2014) denomina de educação bancária, que em nada contribui para a ampliação e o aprofundamento na leitura da realidade pelos sujeitos.

\section{Considerações Finais}

Buscamos neste trabalho argumentar acerca das potencialidades de conceber currículos na área de Ciências da Natureza, estruturados a partir de temas identificados junto à comunidade escolar, sobretudo ao trabalharmos com sujeitos do campo que foram historicamente excluídos do acesso a uma educação de qualidade e da permanência nela.

Ao narrar e avaliar a experiência da primeira fase do PRP, buscamos argumentar em favor de alguns pressupostos que acreditamos serem fecundos na formação de nossos licenciandos: a) a decisão de sair do âmbito da universidade e da escola e ouvir o que a comunidade tem a dizer, fato que permitiu a oferta de aprendizagens essenciais aos licenciandos, conhecimentos em vias de se perder com a morte dos mais idosos; b) o entendimento da escrita como um processo que auxilia a organização das ideias e a autoria na defesa daquilo que acreditamos para o nosso processo formativo; e c) as mudanças na concepção do currículo e a importância de construir currículos que tenham sentido para os sujeitos, para além da introdução de novas técnicas de ensino.

Enfim, um dos principais destaques é a respeito da docência como profissão, que se manifestou durante a atuação desses professores, como bolsistas do PRP, deflagrando o processo de construção e de reelaboração da identidade docente. Certamente, os desafios são muitos e, com isso, caminhamos com as circunstâncias históricas que nos levam a inquietações nascidas no interior da práxis humana, 
buscando um diálogo com o conhecimento necessário e em dívida com os sujeitos do campo, suas lutas e seus direitos!

Referências

ARROYO, M. G. A Educação Básica e o Movimento Social do Campo. In: ARROYO, M. G.; CALDART, R. S.; MOLINA, M. C. (org.). Por uma Educação do Campo. 5. ed. Rio de Janeiro: Vozes, 2011. p. 65-86.

BRASIL. Decreto n. 7.352, de 4 de dezembro de 2010. Dispõe sobre a Política de Educação do Campo e o Programa Nacional de Educação na Reforma Agrária. Brasília, DF: Imprensa Nacional, 2010. Disponível em: http://portal.mec.gov.br/docman/marco-2012-pdf/10199-8-decreto-7352-de4-de-novembro-de-2010/file. Acesso em: 31 jan. 2018.

EMILIANO, D. Revitalização dos saberes e práticas Kaingang sobre as plantas tradicionais como proposta de educação ambiental na Terra Indígena Ligeiro. 2015. 163f. Dissertação (Mestrado) - Programa de Pós-Graduação em Educação Ambiental, FURG, Rio Grande, 2015.

FREIRE, P. Pedagogia da esperança: um reencontro com a pedagogia do oprimido. 23 ed. São Paulo; Rio de Janeiro: Paz e Terra, 2016.

FREIRE, P. Pedagogia do Oprimido. 58. ed. Rio de Janeiro: Paz e Terra, 2014.

FREIRE, P. Extensão ou Comunicação? 15. ed. São Paulo: Paz e Terra, 2011.

FREIRE, Paulo. A importância do ato de ler: em três artigos que se completam. 49. ed. São Paulo: Cortez, 2008. 
MOLINA, M. C.; HAGE, S. M. Riscos e potencialidades na expansão dos cursos de licenciatura em Educação do Campo. RBPAE, [S.l.], v. 32, n. 3, p. 805-828, set./dez. 2016.

PARANÁ. (Estado). Secretaria de Estado da Educação. Superintendência da Educação. Diretoria de Políticas e Programas Educacionais. Coordenação de Desafios Educacionais Contemporâneos. Curitiba: SEED-PR, 2008.

TOZONI-REIS, Marília Freitas de Campos. Metodologia da Pesquisa. 2. ed. Curitiba: IESDE Brasil S.A., 2010. 
